\title{
ECOCURE BLUE - NEW COLD BOX SYSTEM WITH ULTRA-HIGH EFFICIENCY AND AS LOW AS POSSIBLE EMISSIONS
}

P. H.VACELET, ASK Chemicals GmbH, Hilden, Germany,Pierrehenri.E-mail:Vacelet@ask.chemicals.com D.TÁBORSKÝ, ASK Chemicals Czech s.r.o., Czech Republic.E-mail: dan.taborsky@ask-chemicals.com

By omitting materials subject to the labeling requirement in part 1 cold-box resin, Düker GmbH from Laufach can achieve an impressive reduction in emissions.

Emission and workplace exposure limit values represent major challenges for foundries, and are becoming increasingly important due to every stricter statutory regulations. In particular, compliance with emission guidelines is essential in safeguarding company sites, and is now of equal significance as technical and economic issues. Modern foundries such as Düker GmbH from Laufachpursue a sustainable corporate policy in which the three pillars of cost-effectiveness, social responsibility and environmental protection are accorded equal importance. Düker's example shows how the use of the new ECOCURE BLUE technology supports environmental protection and occupational health and safety, while also facilitating efficient, highly productive core production.

\section{ECOCURE BLUE - НОВАЯ COLD-ВOX-СИСТЕМА С УЛЬТРАВЫСОКОЙ ЭФФЕКТИВНОСТЬЮ И МАКСИМАЛЬНО НИЗКИМИ ВЫБРОСАМИ}

П. ВАСЕЛЕT, ASK Chemicals GmbH, Hilden, Германия, Pierrehenri.E-mail:Vacelet@ask.chemicals.com Д. ТАБОРСКИ, АSК Chemicals Czech s.r.o., Республика Чехия. E-mail: dan.taborsky@ask-chemicals.com

\footnotetext{
Исключая некоторые материалы, наличие которых предусмотрено требованиями маркировки для Cold-Box-смоль часть 1, фирма Düker GmbH (2. Лафаш), смогла добиться впечатляющего сокращения вредных выбросов.

Вредные выбросы и предельные значения воздействия их на рабочем месте являются одной из главных проблем для литейного производства и становятся все более важными из-за принятия более строгих нормативных актов. В частности, имеет такое же большое значение в безопасности на территории компании, как и технические и экономические вопросы.

Современные литейные предприятия, такие, как Düker GmbH (2. Лафаш), проводят устойчивую политику на основе трех принципов: экономической эффективности, сочиальной ответственности и защить окружающей среды. Пример фирмы Düker показывает, как использовать новую технологию ECOCURE BLUE для защиты окружающей среды, профессионального здоровья и безопасности работающих, а также для эффективного и высокопродуктивного основного производства.
}

The medium-sized company, Düker is regarded as one of the leading manufacturers of valve bodies and pressure pipe formed parts for drinking water and gas supply as well as of pipes and formed pieces for drainage technology (Fig. 1). The company's expertise starts with the design phase and extends across simulation, model construction, casting and processing right up to coating. Düker also produces enameled components and pipes with high acid resistance for plant construction in the chemical and pharmaceutical industry.

A further business field is jobbing casting, where the focus is on producing parts for robotics, the mechanical engineering industry and the railway industry. Based in Laufach, in Bavaria, the company sees itself as a pioneer in its sector and always aims at developing new products and solutions for its customers. One example of this is the series production of a mixed crystal ferritic cast iron, which only recently was listed in DIN EN 1563 as a new ma-

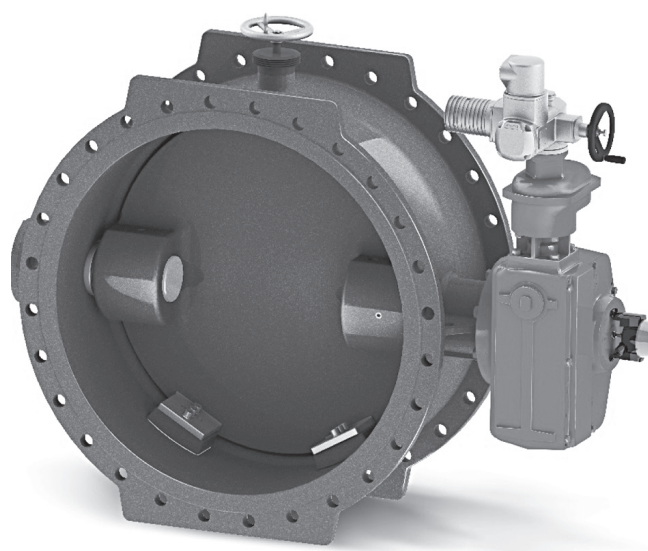

Fig. 1. Düker produces valve bodies and pressure pipe formed parts for drinking water and gas supply as well as pipes and formed pieces for drainage technology 


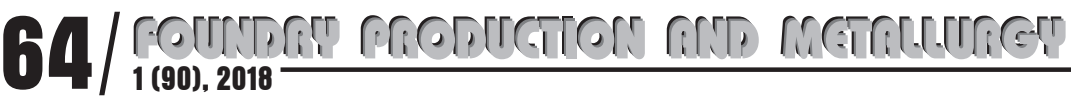

terial group. Düker has been working intensively with this new material since 2012 and has been producing it, in series production, since 2014. Düker's customers are thus offered new opportunities to optimize components with improved machinability.

The company subjects its products to the very highest quality standards and introduced a modern quality management system in accordance with DIN EN ISO 9001 as far back as 1993. The company's commitment to ecological and social issues is made clear by its use of important management systems. Düker operates a certified environmental management system in accordance with DIN EN ISO 14001 and an energy management system in accordance with DIN EN ISO 50001, complemented by a certified occupational health and safety management system in accordance with BS OHSAS 18001.

\section{EMISSIONS IN THE CASTING PROCESS}

Solvents and highly volatile materials, which are contained in the cold box binder system, are classified as potentially harmful to the environment and to employee health. The new cold box technology platform from ASK Chemicals GmbH, ECOCURE BLUE, now allows foundries, in the cold box part 1, to completely avoid using ingredients which are subject to compulsory labeling (Fig. 2), and to considerably reduce BTX emissions, particularly benzene. One of the first users of this technology is Düker. The ECOCURE BLUE High Efficiency (HE) systems combine economic and environmental advantages throughout the entire process, without compromising, when it comes to reactivity, strength and the casting result.

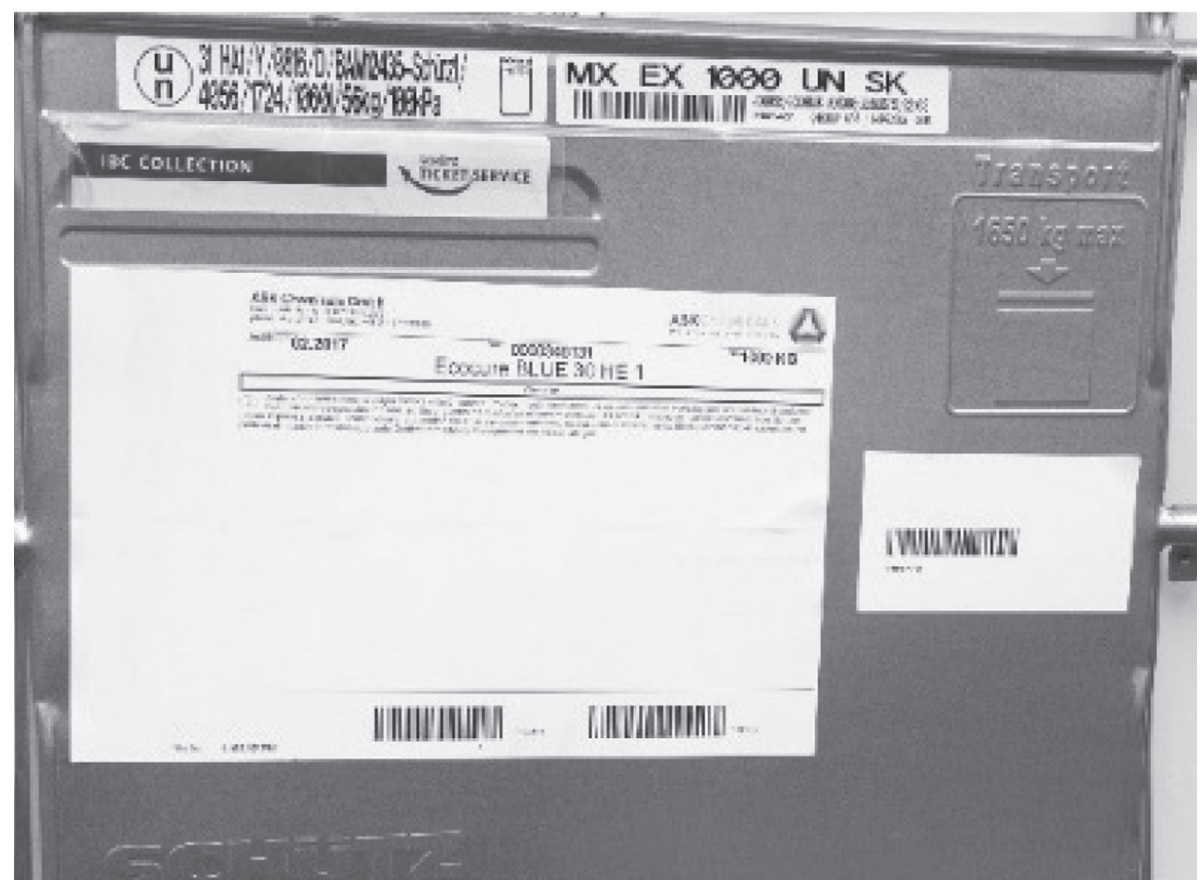

Fig. 2. ECOCURE BLUE is the world's first marking-free cold box binder part 1

Most air pollutants, in foundries, arise during casting. A large part of the solvents evaporate from the core and mould, due to the high temperatures involved as well as residual monomers such as phenol, formaldehyde and other low molecular weight polymers. Subsequently the polyurethane polymer chains thermally decompose due to the available oxygen in the mould cavity, and within the mould and cores themselves, i. e. combustion. Then as the oxygen is largely consumed partial thermal decomposition occurs known as pyrolysis. This results in products which include BTX (benzene, toluene and xylene), $\mathrm{CO}$ and $\mathrm{NO}_{\mathrm{x}}$, as well as many other pollutants.

The developments over the past few years have aimed specifically at preventing solvent emissions during core production, or at least discharging them in a managed manner. «At the same time, it was and is necessary to take into consideration the growing and future demands placed on the whole foundry process when making specific modifications to the binder system,» declares Pierre-Henri Vacelet, Market Manager for the binder division at ASK Chemicals. The catalyst consumption and the amine gassing time are also important factors relating to both the environmental and economic performance. Also during recent developmentsin binders, a primary focus was placed on attempting to influence the odor and / or the BTX substances that are released within the process. 


\section{BETTER CURING EFFICIENCY WHILE ALSO LOWERING THE BINDER QUANTITY}

Due to stricter regulations, which prescribe a drastic reduction in phenol emissions from 2020 onwards, Düker has been attempting, since 2013, to lower the level of all highly volatile aromatic materials, like phenol and other aromatics like BTX, and to change the processes accordingly. "At that time, in our search for support, we approached ASK Chemicals as an innovation and technology partner, to help reduce the benzene emissionsduring casting, in particular, at our production site in Laufach,» reports Michael Poetzsch, foundry manager at Düker (Fig. 3). The initial approach was one where the binder content of the cold box cores was reduced as far as possible (without compromising the technical or quality-related properties of the core, or the quality of the cast part), and the emissions are thus lowered. An initial success was achieved through the use of the cold box «High Efficiency» system ECOCURE HE from ASK Chemicals, which was incorporated into series production in 2014.

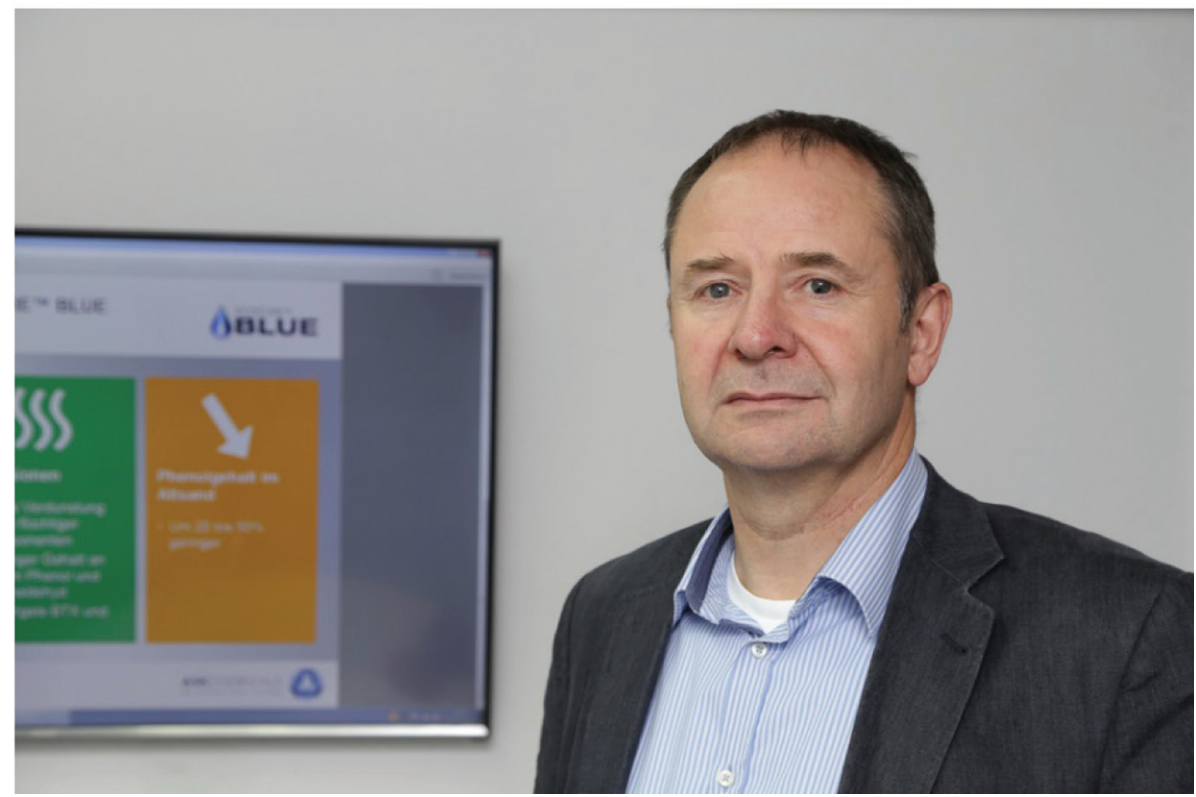

Fig. 3. Michael Poetzsch is very happy with the reduction in emissions that Düker achieved by changing the cold box binder system

Building on the knowledge that free monomers arise within fractions of a second after casting due to vaporization, and, subsequently BTX and $\mathrm{NO}_{\mathrm{X}}$ emissions arise as the casting phase continues, ASK Chemicals developed this «High Efficiency» binder technology as far back as 2008. Its high performance allows the binder quantity to be reducedfor the same core performance. «The mechanical properties of the sand cores which were produced with these HE systems were comparable with those of conventional products, despite the reduction in binder. The increase in reactivity led to a considerable increase in initial strength, which made it possible to conduct the remaining processing steps safely within a shorter time,» states Vacelet. The resulting amine saving is also reflected in the odor as well as the lower material costs and a less pronounced tendency towards sticking. As a consequence of its success, the ECOCURE technology has undergone constant further development.

In order to further investigate the influence of the composition of the binding agent on the composition of emissions, ASK Chemicals has made particular use of its own»Hoodstack» casting emissions capture and analysis method in recent years, in addition to other methods. This analysis, in conjunction with ASK Chemical's development foundries, makes it possible to provide real casting emission evidence of volatile organic compounds, carbon monoxide, carbon dioxide, gaseous nitrogen- and sulfur-based emissions as well as to quantify lead based compounds.

\section{NO MORE INGREDIENTS SUBJECT TO COMPULSORY LABELING IN PART 1 BINDER}

A systematic reduction in the free monomer content, particularly the free phenol, initially took second place as the development of such a solution was extremely complex and needed modification of the existing production systems. Together with Düker, these modifications were implemented from June 2015 onwards. Just a few months later, in September of the same year, ASK Chemicals presented initial laboratory prototypes, and in early 2016, the results of the final developments. The final outcome was the cold box technology, ECOCURE BLUE, based on ultra-low free phenol resin. All catalysts available on the market, the usual sand qualities as 


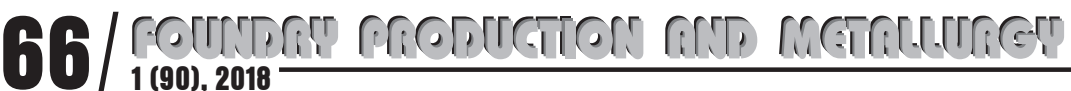

well as numerous sand additives can be used with this binder. With the exception of Di Basic Ester (DBE) and only in Germany, ECOCURE BLUE does not contain any components that have to be mentioned due to their workplace exposure limit value. Only the part 2 of the cold box formulation is unavoidably based on isocyanate, which must be declared. «Part 1 of the new cold box binder no longer bears any hazardous substance symbols. This is a huge relief for us regarding the transportation and storage of the binder. However, it is first and foremost a clear advantage for occupational health and safety and an important signal for our employees,» emphasizes Poetzsch. With the ECOCURE BLUE system, the odor is less noticeable to employees compared to the previous system and this system can be classified as workplace-friendly thanks to its low hazard composition (Fig. 4).

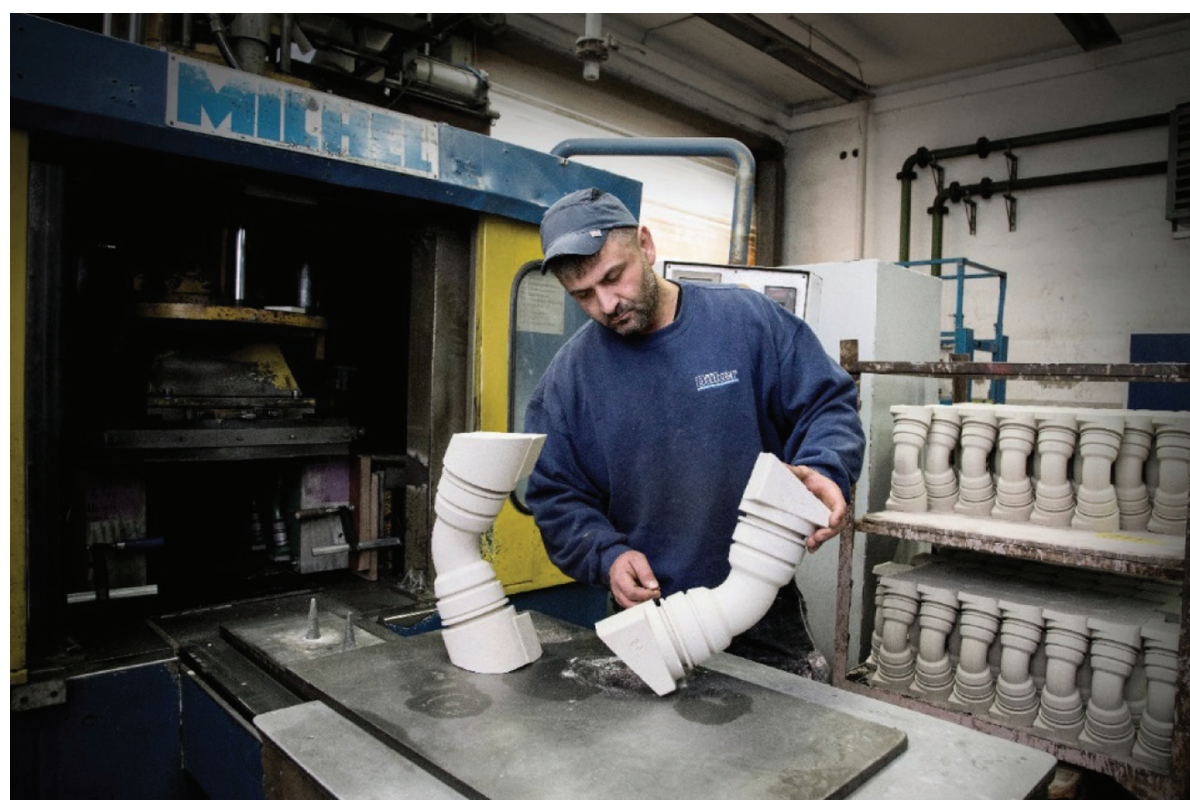

Fig. 4. Employee reaction was very positive with regard to the odor as well.

This was regarded as less pronounced than in the previous systems

Developed for iron and steel casting, the system is also suitable for the production of hydraulic components, turbochargers, brake disks and engine blocks. Düker, in Laufach, uses the ECOCURE BLUE technology to produce the majority of its core product range, from parts with filigree geometries weighing just a few grams up to molded cores weighing $100 \mathrm{~kg}$ (Fig. 5, a, b).

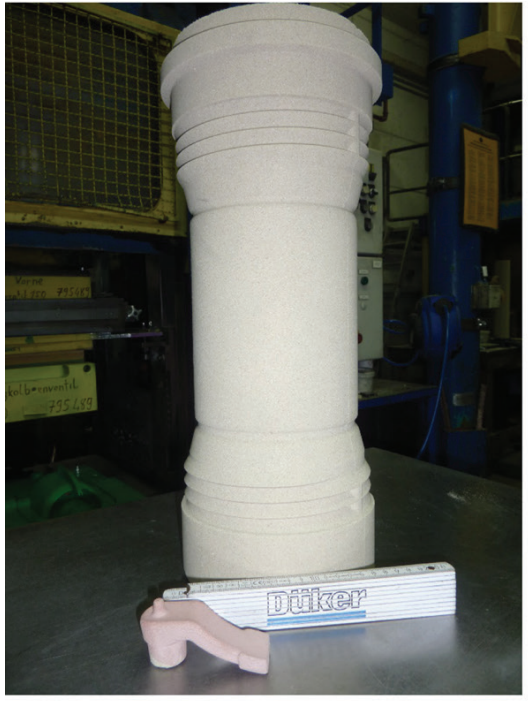

$a$

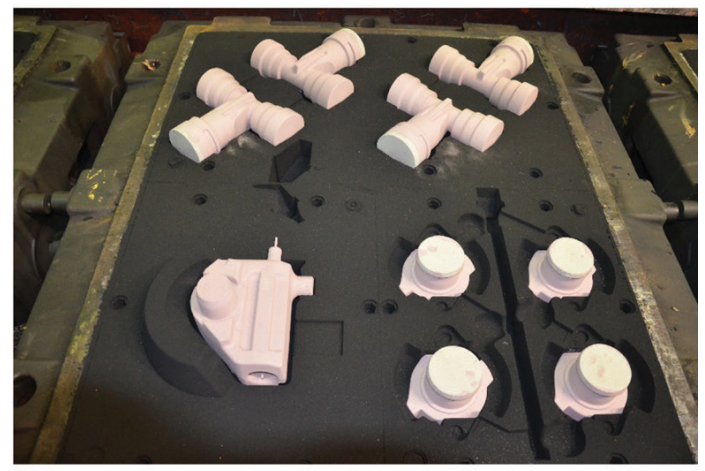

$b$

Fig. 5. Düker produces most of its core product range with the new binder ECOCURE BLUE 
The use of the ECOCURE BLUE platform makes it possible to lower the emissions throughout the entire process from core production and casting, right up to demolding - without having to forego the advantages of the original high-efficiency technology with its ability to systematically optimize low binder additions with high initial strengths. "This is of the greatest significance, particularly in light of the fact that the cycle times are required to get shorter, the cast parts and geometries more complex, and the walls ever thinner,» confirms Poetzsch. The ECOCURE BLUE solution thus combines productivity-increasing factors such as very good mechanical strengths, an excellent reactivity and outstanding casting results with increased environmental and health and safety protection.

\section{BENZENE EMISSIONS IN THE AIR LOWERED BY 66\%}

By means of a long-term analysis, conducted over four months followed by the introduction for series production, Düker showed that a binder reduction of $7 \%$ was possible, even compared with the efficient ECOCURE HE technology (Fig. 6). Compared with a conventional solution still in use in 2014, the addition of binder was reduced by $22 \%$. Through the use of the new ECOCURE BLUE technology, the BTX emission concentrations were lowered across the board, and in particular those of the benzene emissions during the casting process, by $66 \%$. These measurement results were provided from an independent measurement institute that was commissioned to conduct the BTX measurements (Fig. 7). In addition, a 34\% reduction in BTX emissions from the green sand / used sand was observed compared to the previous system.

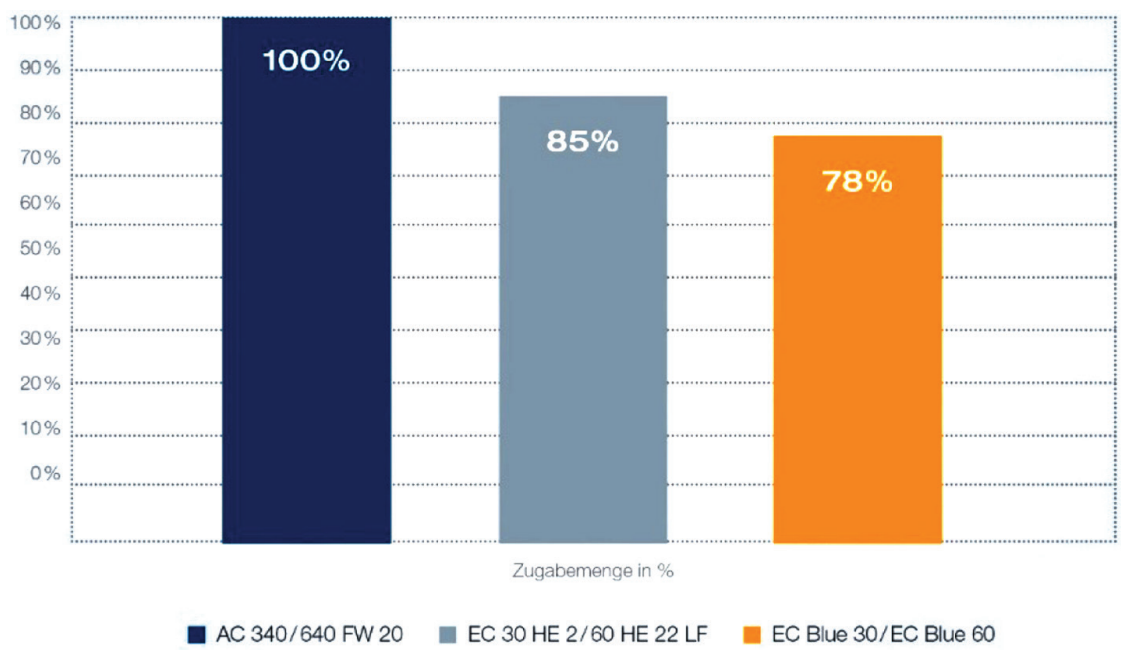

Fig. 6. Reduction in cold box binder quantities

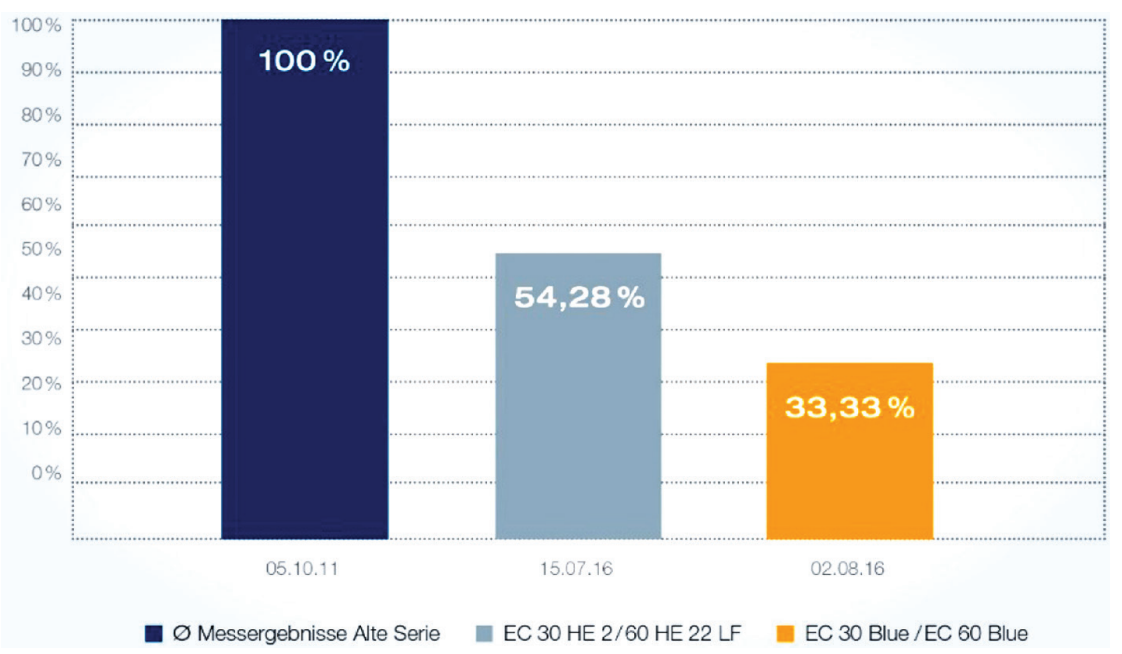

Fig. 7. Progression of the benzene emissions

«It is important to us to discharge as few emissions as possible into our environment and to make products as odor-neutral as possible. In addition to smaller tests conducted by ourselves, we also had long-term tests conducted by an independent institute, from the start of binder evaluations,» summarizes Poetzsch. The current 
emission limit value of $5 \mathrm{mg} / \mathrm{m}^{3}$ of air was complied with (thanks to the new binder), while the previous system was slightly above this limit. By optimizing the ECOCURE BLUE system to the sand quality used, a binder reduction was achieved so the overall impacts on costswere neutral, if not lower. So that this latest technology does not necessarily raise the costs of the sand mix.

«The new binder meets all our expectations regarding the core sand system's strength properties and the cast part quality that results from this. We are very happy with the result. The introduction of the new binder can thus be regarded as a long-term conversion across the entire line as we can produce high-value cast parts reliably and cost-effectively in this way,» says Poetzsch happily. 